\title{
Development of an Interval-Based Evacuation Management Model in Response to Nuclear-Power Plant Accident
}

\author{
L. Guo ${ }^{1}$, Y. P. Li $^{2}$, G. H. Huang ${ }^{1, *}$, X.W Wang ${ }^{2}$, and C. Dai ${ }^{2}$ \\ ${ }^{1}$ Faculty of Engineering and Applied Science, University of Regina, Regina, SK S4S 0A2, Canada \\ ${ }^{2}$ MOE Key Laboratory of Regional Energy and Environmental Systems Optimization, Resources and Environmental Research Academy, North \\ China Electric Power University, Beijing 102206, China
}

Received 9 October 2011; revised 25 June 2012; accepted 28 July 2012; published online 27 December 2012

\begin{abstract}
Nuclear-power-plant emergency management is very important, which can be used to avoid nuclear accident and radiation leak accident and the emergency action swiftly taken beyond the normal work procedure to mitigate the accident consequences. Evacuation management for large crowds after accidents involves a number of processes and factors with socio-economic and environmental implications. These processes and factors, as well as their interactions, are associated with a variety of uncertainties. In this study, an interval-based evacuation management (IBEM) model is developed in response to such challenges, based on interval-parameter linear programming (ILP) technique that can tackle uncertainties presented as interval values. The IBEM model is applied to a case study and then solved through an interactive algorithm that does not lead to more complicated intermediate submodels and has a relatively low computational requirement. Two scenarios are analyzed based on different policies of total capital considerations. A number of decision alternatives could be directly generated based on results from the IBEM model, which provide bases for in-depth analyses of tradeoffs among evacuation population, system cost, and constraint-violation risk.
\end{abstract}

Keywords: decision making, evacuation management, interval analysis, nuclear accident, optimization, uncertainty

\section{Introduction}

Energy is crucial in supporting people's daily life and continued human development (Amin and Gellings, 2006). Over the past decades, energy supply/demand have been steadily increasing in response to population growth, economic development and life standard improvement throughout the world. The world energy demand is growing at a rate of approximately $1.6 \%$ per year, and is expected to reach about 700 $\times 1018 \mathrm{~J} /$ year by 2030 (Pękala et al., 2010). At the same time, fossil-fuel reserves are continuously shrinking, and its price is gradually rising, posing challenges for decision makers in deciding whether new electric-power utilities (like nuclear power facility) should be established to satisfy the increasing energy demand (Cai et al., 2009; Birant, 2011; Li et al., 2011). However, accidents at the nuclear power plants initiated by equipment malfunctions, operator errors or external initiators (e.g., earthquakes, floods and tornadoes) are great obstacles to sustainable development of using nuclear energy. They can significantly affect the long-term viability of society and economy and lead to serious adverse impacts on the people and the environment. Therefore, the safety of nuclear power plants is

\footnotetext{
* Corresponding author. Tel.: +1 306 5854095; fax: +1 3065854855 .

E-mail address: gordon.huang@uregina.ca (G. H. Huang).
}

ISSN: 1726-2135 print/1684-8799 online

(C) 2012 ISEIS All rights reserved. doi:10.3808/jei.201200220 an important issue in the discussion regarding future scenarios for power generation.

Previously, a number of studies were undertaken to analyze accident risks at nuclear power plants (Ravindra, 1990; MacGregor-Smith, 1991; Slaper and Blaauboer, 1998; Hayns, 1999; Davies, 2002; Strupczewski, 2003; Zhou et al., 2011). These studies mainly estimated the frequencies and consequences of different accidents at the power plants and to identify the significant equipment and system failures that could lead to various accidents. The failures could be initiated by internal events such as equipment malfunctions or unavailabilities, and operator errors; they could also be initiated by external events such as earthquake, flood, fire and tornado. For example, Ravindra (1990) examined the frequencies and consequences of severe core damage, serious radiological releases, and consequences in terms of early fatalities, long-term adverse health effects and property damage, and to identify significant contributors to nuclear power plant risks due to seismic disaster. In the research of Slaper and Blaauboer (1998), an integrated assessment of probabilistic cancer mortality risks due to possible accidental releases from the European nuclear power plants was conducted; results provided a probabilistic view of the risks involved as well as the major areas at risk. Strupczewski (2003) presented the results of estimates of nuclear-power plant safety based on probabilistic safety analyses and discusses the means used to decrease core damage factors, large release frequency and cancer deaths due to nuclear accidents. Generally, the above studies focused on the evaluation of acci- 
dent probabilities and subsequent release risks for nuclear power plants. It is not possible to eliminate the nuclear disasters; however, strengthening the disaster response and emergency management can largely mitigate their negative effects.

Disaster response is important in preparation for many accidents such as earthquakes, tidal waves, destructive fires, nuclear power accidence (Sorensen et al., 1992; Drabek, 1999; Cova and Justin, 2003). Emergency evacuation and logistics support are two major activities in disaster response (Yi and Ozdamar, 2007). Emergency evacuation activities take place during the initial response phase until the lives and property of victims can deserve the protection and release the further threat from disasters. Once accident occurring, a large number of people at one or several predetermined locations and need to be evacuated afterwards. The mass movement of persons from the accident sites to several destinations through various vehicles is emergency-related evacuation. However, evacuation of such large crowds in a safe and timely manner is an extremely difficult task (Chiu et al., 2007). Evacuation management for large crowds after nuclear power accidents involves a number of processes and factors with socioeconomic and environmental implications, which pose a challenge to decision makers (Strupczewski, 2003; Li and Huang, 2012). For example, emergency evacuation systems often contain the zone for evacuating to be agreed upon, the population at the risk to be identified, the time of evacuation to be predicted, the shelter of refugees to be chosen, the safe routes of evacuation to be adopted, and the levels of logistics to be offered; moreover, many related processes and/or factors are complex with multi-period, multi-layer, and multiobjective features. Therefore, development of science-based tools to facilitate accidentrelated evacuation management is imperative.

Research works related to evacuation management were scant and largely relied on qualitative methods before 1979 (Urbanik, 2000). Since then, increasing research efforts have been made, with a variety of mathematical programming methods being proposed for systematically analyzing evacuation management problems. For example, Yamada (1996) studied a city emergency evacuation planning problem using two network flow models, where the first model sought the shortest paths on an undirected graph and assigned each evacuee to a corresponding shelter; then, the shortest path network was transformed to a minimum cost flow problem by adding capacities in each shelter. Hamacher and Tjandra (2001) gave an overview for mathematical modeling of evacuation problems; they especially presented variations of discrete time dynamic network flow problems to model evacuation problems (e.g., maximum dynamic flows, earliest arrival flows, quickest path$\mathrm{s}$ and flows, or continuous time dynamic flows). Cova and Johnson (2003) presented a mixed-integer linear programming model to identify optimal lane-based evacuation routing plans and prevent traffic crossing conflicts at intersections. Liu et al. (2006) presented a two-level integrated optimization system for identifying optimal evacuation plans; the high-level optimization maximized the throughput during a given evacuation duration, while the low-level optimization minimized the total time of the whole operation, including transportation time and waiting time. Saadatseresht et al. (2009) combined multiobje- ctive evolutionary algorithms and geographical information system for evacuation planning, where a three-step approach for determining the distribution of evacuees into the safe areas (i.e., deciding where and from which road each evacuee should go) was proposed. Stepanov and Smith (2009) proposed an integer programs model to decide the routes in emergency evacuation planning, where $\mathrm{M} / \mathrm{G} / \mathrm{c} / \mathrm{c}$ state dependent queuing models were used to cope with congestion and time delays on road links. Tan et al. (2009) developed an inexact fuzzy robust programming model for evacuation management for supporting the management of event-related evacuation; parameters presented as interval numbers and/or fuzzy boundary intervals were acceptable as uncertain inputs, such that the uncertainties can be directly communicated into the optimization process.

Although many research efforts have been dedicated to evacuation management, few of them concerned evacuation management for nuclear power plant accidents. Moreover, most of the previous studies regarding uncertainty examination in evacuation management were limited to sensitivity analyses (Urbanik, 2000; Chu et al., 2007). There was a lack of direct communication for uncertainties in the modeling efforts, particularly for evacuation management of nuclear power plant accidents. Nuclear power plants pose sever threats to people and environment, including health risks and environmental damage from uranium mining, processing and transport, the risk of nuclear weapons proliferation or sabotage, and the unsolved problem of radioactive nuclear waste (Giugni, 2004; GIEREC, 2007; NENCR, 2010). Nuclear reactors themselves are enormously complex machines where many things can and do go wrong, and there have been many serious nuclear accidents in terms of human injuries and property damage (Sovacool, 2008; Stephanie, 2009). Besides, in emergency evacuation management for nuclear power plant accident, uncertainties are attributed due to the randomness that are inherent in nature and due to the lack of sufficient data related to the chances of their occurrence and potential consequences. Uncertainties exist with respect to the associated crowd, evacuation time, traffic vehicle, economic cost, as well as other impact factors, which will affect the optimization processes and the decision schemes generated. In order to obtain timely, safe, and efficient evacuation schemes under such uncertainties and complexities, it is desired that transportation resources and services be efficiently used without significant disturbance over the existing municipal traffic and environmental quality.

Therefore, the objective of this study is to develop an interval-based evacuation management (IBEM) model for planning of the movement of persons from dangerous areas to safe areas when nuclear-power plant accident occurs. The IBEM model will be based on interval-parameter linear programming (ILP) technique for tackling uncertainties that cannot be quantified as distribution or membership functions, since interval values are acceptable as its uncertain inputs. Interval solutions will be analyzed and interpreted to generate multiple decision alternatives under various system conditions, and thus help decision makers to identify desired crowd-evacuation plans under uncertainty. 


\section{Model Development}

\subsection{Statement of Problem}

Human populations are at risk from many hazards, some man-made and others stemming from natural causes; the former include risks such as escapes of hazardous substances such as chemicals, accidents in nuclear power plants and collapses of large scale civil engineering projects such as dam walls; the latter include hazards such as floods, earthquakes and hurricanes (Pidd et al., 1996; Bretschneider and Kimms, 2011). As opposed to natural disasters that can be anticipated, nuclear-power plant accidents are often sudden and unexpected. Even if sometimes we do have information about a possible accident, we will not know for sure when, where and how the accident will occur. This lack of information poses great challenges on those responsible for security, in particular on their ability to respond fast whenever necessary with flexibility, efficiency and coordination (Hamza-Lup et al., 2007). Therefore, techniques for responding to nuclear accidents after they occur are of great interest and critical importance. On the other hand, nuclear accidents can lead to large scale environmental emissions if in addition to severe damage to the reactor core a failure of the security systems occurs. Such accident scenarios are related to the construction and maintenance of the plant and its safety systems, in relation to the external activities (e.g., earthquake, flood, fire and tornado) in the area, the materials used, and the operational and safety procedures adopted. Therefore, nuclear emergency management is very important, which is to avoid nuclear accident and radiation leak accident and the emergency action swiftly taken beyond the normal work procedure to mitigate the accident consequences. In such an emergency situation, evacuation action has to be conducted in order to displace people from the dangerous place to a safer place, and it usually needs to be done in a hurry. It is necessary to prepare evacuation plans in order to have a good response in an emergency situation. One of biggest challenges in developing such an evacuation plan is in determining the distribution of evacuees into the safe areas (i.e., deciding where and from which road each evacuee should go, and how many transfer vehicles should be prepared to evacuate a threatened population) (Saadatseresht et al., 2009). Evacuations require a particularly thorough analysis because of the substantial logistical complexities involved in their implementation. In this regard, it is noteworthy that emergency planning zones of one nuclear power plant cover a very large area (e.g., over 300 mile square or $900 \mathrm{~km}^{2}$ ), and contain hundreds of thousands of people (Urbanik, 2000).

A nuclear-accident evacuation management system involves a multitude of processes with social, economic, and environmental implications, such as organization of salvage, gathering of population, grouping of evacuees, allocation of transportation resources, provision of services, and planning of evacuation routes. These processes are associated with a number of factors, such as amount of traffic vehicles to be employed, number of people to be evacuated, destinations of evacuees, limitations of evacuation times, budgets of the evacuation, capacities of shelters and hospitals, and environ- mental regulations of the involved areas. There are complex interactions between these processes and factors. Moreover, accident evacuation practices for large crowds are subject to extensive uncertainties, which further complicate the problem. These uncertainties are normally resulted from unforeseeable incidents and deviations in subjective judgments. They are ubiquitous in many system components and may affect processes of data investigation, modeling computation, and results presentation (Li et al., 2011). In fact, deterministic information can hardly be obtained in evacuation efforts. For example, accident scale and evacuation population cannot be predictable due to its unexpected breaking out (i.e., caused by equipment malfunctions, operator errors, or natural disasters), which makes it impossible to conduct proactive planning and analysis at the pre-evacuation stage, leading to evacuation schemes being highly uncertain (e.g., locations, scales, and schedules); evacuees are mostly evacuated from multiple threaten areas to different destinations (shelters or hospitals).

Generally, it is difficult to plan the emergence evacuation because: (i) there are a variety of reasons to cause nuclear accidents; (ii) the disasters are often too difficult to predict or cannot be effectively identified; (iii) there are a lack of sufficient data; (iv) there are deficiencies of the scientific knowledge on these accidents; and (v) there are a number of complexities and uncertainties associated with the accidents and modeling efforts. These complexities as embedded within evacuation management systems are far beyond the capabilities of conventional optimization techniques. There is also a demand for studies that incorporate various isolated system components within a general framework to generate robust decision support for nuclear-accident evacuation management.

\subsection{Interval-Parameter Linear Programming}

Interval-parameter linear programming (ILP) is suitable for tackling uncertainties that cannot be quantified as membership or distribution functions, since interval numbers are acceptable as uncertain inputs for the ILP (Huang et al., 1992; Fan and Huang, 2012). ILP allows uncertain information to be directly communicated into the optimization process and resulting solutions, such that feasible decision alternatives can be generated through interpretation of the interval solutions according to projected applicable conditions. An ILP model can be defined as follows (Huang et al., 1992):

$\operatorname{Min} f^{ \pm}=C^{ \pm} X^{ \pm}$

subject to:

$A^{ \pm} X^{ \pm} \leq B^{ \pm}$

$X^{ \pm} \geq 0$

where $A^{ \pm} \in\left\{R^{ \pm}\right\}^{\mathrm{m} \times \mathrm{n}}, B^{ \pm} \in\left\{R^{ \pm}\right\}^{\mathrm{mx} 1}, C^{ \pm} \in\left\{R^{ \pm}\right\}^{1 \times \mathrm{n}}, X^{ \pm} \in\left\{R^{ \pm}\right\}^{\mathrm{n} \times 1}$, and $R^{ \pm}$denotes a set of interval numbers; the '-' and ' + ', 


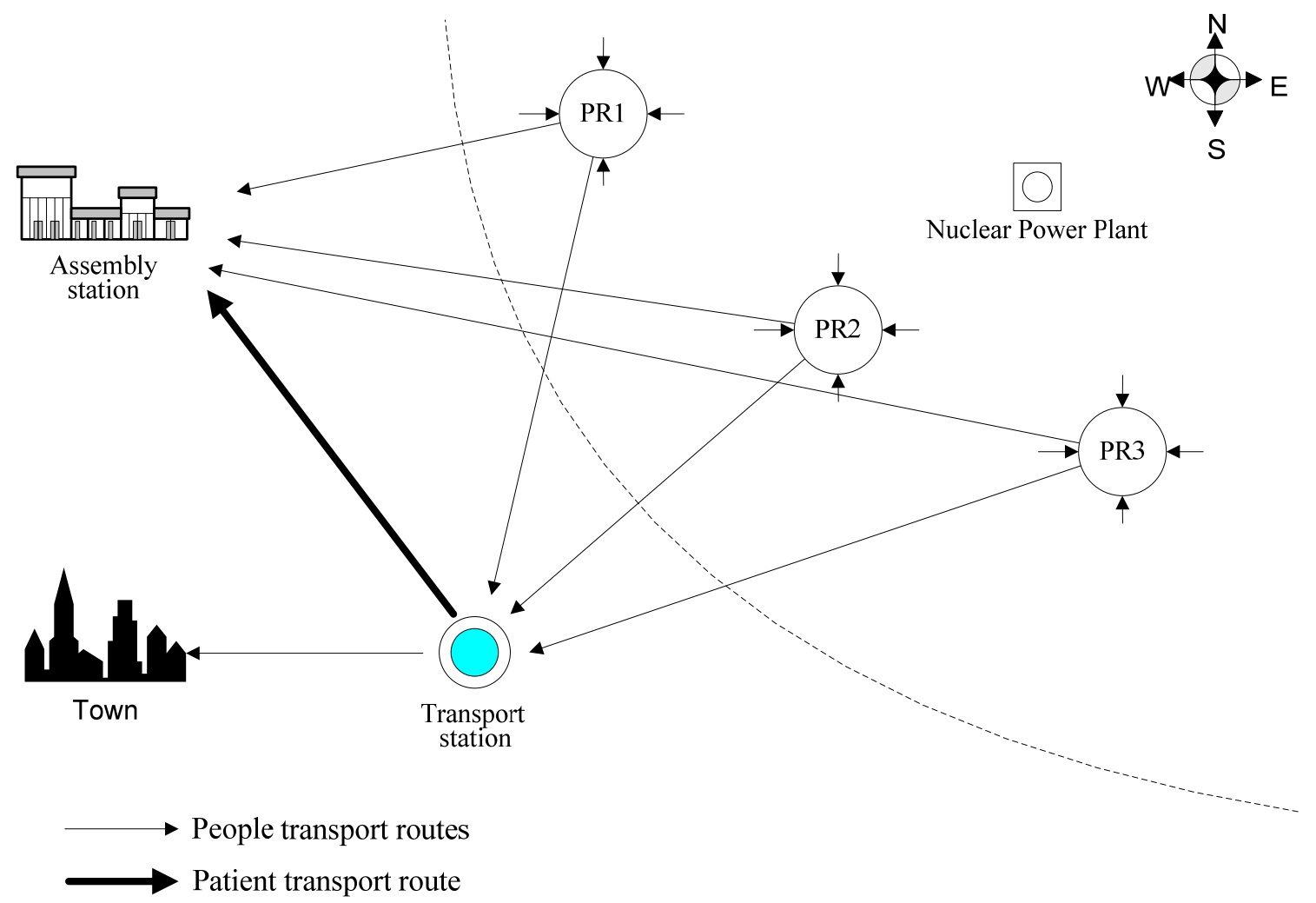

Figure 1. The study system (note: PR denotes places of refuge).

superscripts represent lower and upper bounds of an interval parameter/variable, respectively. According to Huang et al. (1992), ILP can be directly transformed into two deterministic submodels, which correspond to the lower and upper bounds of the objective-function value. By solving the two submodels, interval solutions can be obtained and be used for generating a range of decision options (Huang and Cao, 2011). In detail, the first submodel corresponding to $f^{-}$(when the objective function is to be minimized) can be formulated as follows (assume that $b_{i}^{ \pm}>0$ and $f^{ \pm}>0$ ):

$\operatorname{Min} f^{-}=\sum_{j=1}^{k_{1}} c_{j}^{-} x_{j}^{-}+\sum_{j=k_{1}+1}^{n} c_{j}^{-} x_{j}^{+}$

subject to:

$\sum_{j=1}^{k_{1}}\left|a_{i j}\right|^{+} \operatorname{Sign}\left(a_{i j}^{+}\right) x_{j}^{-}+\sum_{j=k_{1}+1}^{n}\left|a_{i j}\right|^{-} \operatorname{Sign}\left(a_{i j}^{-}\right) x_{j}^{+} \leq b_{i}^{+}, \forall i$

$x_{j}^{ \pm} \geq 0, \forall j$

where $x_{j}^{ \pm}\left(j=1,2, \ldots, \mathrm{k}_{1}\right)$ are interval variables with positive coefficients in the objective function; $x_{j}^{ \pm}\left(j=k_{1}+1, k_{1}+2, \ldots\right.$, $n)$ are interval variables with negative coefficients. Solutions of $x_{j \text { opt }}^{-}\left(j=1,2, \ldots, k_{1}\right), x_{j \text { opt }}^{+}\left(j=k_{1}+1, k_{1}+2, \ldots, n\right)$ and $f_{\text {opt }}^{-}$ can be obtained from submodel (2). The second submodel corresponding to $f^{+}$can be formulated as follows:
$\operatorname{Min} f^{+}=\sum_{j=1}^{k_{1}} c_{j}^{+} x_{j}^{+}+\sum_{j=k_{1}+1}^{n} c_{j}^{+} x_{j}^{-}$

subject to:

$\sum_{j=1}^{k_{1}}\left|a_{i j}\right|^{-} \operatorname{Sign}\left(a_{i j}^{-}\right) x_{j}^{+}+\sum_{j=k_{1}+1}^{n}\left|a_{i j}\right|^{+} \operatorname{Sign}\left(a_{i j}^{+}\right) x_{j}^{-} \leq b_{i}^{-}, \quad \forall i$

$x_{j}^{+} \geq x_{j \text { opt }}^{-}, j=1,2, \cdots, k_{1}$

$0 \leq x_{j}^{-} \leq x_{j \text { opt }}^{+}, j=k_{1}+1, k_{1}+2, \cdots, n$

Solutions of $x_{j \text { opt }}^{+}\left(j=1,2, \ldots, k_{1}\right), x_{\text {jopt }}^{-}\left(j=k_{1}+1, k_{1}+\right.$ $2, \ldots, n)$ and $f_{\text {opt }}^{+}$can be obtained from submodel (3). Then, through integrating the solutions of the two submodels, interval solutions for the ILP model can be expressed as follows:

$x_{j \text { opt }}^{ \pm}=\left[x_{j \text { opt }}^{-}, x_{j \text { opt }}^{+}\right], \forall j$

$f_{\mathrm{opt}}^{ \pm}=\left[f_{\mathrm{opt}}^{-}, f_{\mathrm{opt}}^{+}\right]$

\subsection{Interval-Based Evacuation Management (IBEM) Model}

In a typical nuclear-power-plant emergency evacuation system (as shown in Figure 1), four main components are 
considered. They are: (i) the victim flow section, which have to be released into the shelters; (ii) makeshift refuge point (MRP) section, where the residents are advised to evacuate themselves to their respective MRPs for emergence relief and wait to be delivered into the long-term settlement place; (iii) transfer station section, which can accept the victim flow from the MRPs and transported this victim flow into long-term settlement place; (iv) long-term settlement place (LSP) section, which is the terminal of the system and the victim flow in LSPs is safe. An interval-based evacuation management (IBEM) model for nuclear power plant accident can be formulated as follows:

$\operatorname{Max} f^{ \pm}=\sum_{i=1}^{I} \sum_{j=1}^{J} \sum_{k=1}^{K} L_{k} x_{i, j, k}^{ \pm}$

subject to:

$x_{i, j, k}^{ \pm} / \alpha \leq F A S_{i, j}^{ \pm}, \forall i, j, k$

$y_{k}^{ \pm} / \alpha \leq V F T^{ \pm}, \forall k$

$\sum_{i=1}^{I} \gamma_{k}^{ \pm} x_{i, 2, k}^{ \pm}=y_{k}^{ \pm}, \forall k$

$\sum_{j=1}^{J} x_{i, j, k}^{ \pm} \geq \beta_{i, k}^{ \pm} P A_{i, k}^{ \pm}, \forall i, k$

$\sum_{i=1}^{I} x_{i, 2, k}^{ \pm} \leq C T^{ \pm}, \forall k$

$\sum_{k=1}^{K} L_{k}\left(\sum_{i=1}^{I} x_{i, 1, k}^{ \pm}+y_{k}^{ \pm}\right) \leq C S^{ \pm}$

$\sum_{k=1}^{K} L_{k} C_{k}\left[y_{k}^{ \pm} D T S+\left(\sum_{i=1}^{I} x_{i, 2, k}^{ \pm}-y_{k}^{ \pm}\right) \times D T C+\sum_{i=1}^{I} \sum_{j=1}^{J} x_{i, j, k}^{ \pm} D_{i, j}\right] \leq T C^{ \pm}$

$x_{i, j, k}^{ \pm} \in N, \forall i, j, k$

$y_{k}^{ \pm} \in N, \forall k$

where:

$f^{ \pm}=$total population flow (person);

$i=$ the type of emergency assembly point, $i=1,2,3$;

$j=$ the type of settlement, $j=1,2$, where $j=1$ for settlement 1 , $j=2$ for settlement 2 ;

$L_{k}=$ the length of time period $k$ (hour);

$k=$ planning time period, and $k=1,2,3$;

$x_{i j k}^{ \pm}=$population flow from emergency assembly point $i$ to settlement $j$ during period $k$ (person/hour); $y_{k}^{ \pm}=$the patient population flow from transfer station to settlement 1 during period $k$ (person/hour);

$F A S_{i j}=$ the maximum vehicle flux in the road from emergency assembly point $i$ to settlement $j$ (vehicle/hour);

$V F T=$ the maximum vehicle flux in the road from transfer station to settlement 1 (vehicle/hour), where only settlement 1 has hospital; $a$ is conversion coefficient;

$\gamma_{k}^{ \pm}=$the proportion of patient population in the evacuation process to settlement 2;

$P A_{i, k}^{ \pm}=$the population aggregation velocity to emergency assembly point $i$ in period $k$ (person/hour);

$\beta_{i, k}^{ \pm}=$the evacuation capability of emergency assembly point $i$ in period $k$;

$C T^{ \pm}=$the capacity of transfer station (person/hour);

$C S^{ \pm}=$the capacity of settlement 1 (person);

$C_{k}=$ the transport cost $(\$ /$ person $/ \mathrm{km})$;

$D T S=$ the distance from transfer station to settlement $1(\mathrm{~km})$;

$D T C=$ the distance from transfer station to settlement $2(\mathrm{~km})$;

$D_{i}=$ the distance from emergency assembly point $i$ to transfer station $(\mathrm{km})$;

$T C^{ \pm}=$the total capital $(\$)$.

The objective of the IBEM model is to obtain a preferred plan for maximizing evacuating population in a finite time; constraints can help define the interrelationships among the decision variables and the vehicle flux, capacity, economic conditions. In detail, constraints (1b) and (1c) denote that the population flow from emergency assembly point to settlement must not exceed the maximum vehicle flux in the road; constraint (1d) means that the patient in the evacuating population would fluctuate in a certain range; constraint (1e) means that a certain percentage population in emergency assembly point should be evacuated during each period; constraint (1f) the population transported to transfer station must not exceed the capacity of transfer station; constraint $(1 \mathrm{~g})$ denotes that the population evacuated to settlement must not exceed the capacity of settlement; constraint (1h) means that the total system cost must not exceed financial budget; constraints (1i) and (1j) mean that the evacuating population should be a integer.

\section{Case Study}

Consider an emergency evacuation system wherein decision makers are responsible for evacuating a large number of people after a nuclear accident event from an original location to multiple pre-specified destinations through public transit. Planning for vehicle allocation and routing strategies is the major concern, which primarily relies on efficient utilization of transportation resources and services. The problem mainly concerned is how to shiftily transfer threatened people from dangerous places to safe places in order to reduce the health and life vulnerability of affected people. Nuclear power accidents often associate with a radiological release and the shelter facilities (i.e., MRPs, LSPs and transfer station sections) 
Table 1. Velocity of Victim Flow into the MRPs

\begin{tabular}{llll}
\hline PA (person/hour) & $\mathrm{k}=1$ & $\mathrm{k}=2$ & $\mathrm{k}=3$ \\
\hline MRP 1 $(\mathrm{i}=1)$ & {$[2450,2500]$} & {$[2700,2750]$} & {$[2550,2600]$} \\
MRP 2 $(\mathrm{i}=2)$ & {$[2450,3500]$} & {$[3600,3650]$} & {$[3500,3600]$} \\
MRP 3 $(\mathrm{i}=3)$ & {$[3200,3250]$} & {$[3400,3500]$} & {$[3100,3200]$} \\
\hline
\end{tabular}

Table 2. Distance and Maximum Traffic Flow of Each Thoroughfare

\begin{tabular}{llll}
\hline From & To & Distance $(\mathrm{km})$ & TF $(\mathrm{pcu} / \mathrm{h})$ \\
\hline MRP 1 $(\mathrm{i}=1)$ & TS $(\mathrm{j}=1)$ & 35 & 210 \\
MRP 2 $(\mathrm{i}=2)$ & TS $(\mathrm{j}=1)$ & 25 & 160 \\
MRP 3 $(\mathrm{i}=3)$ & TS $(\mathrm{j}=1)$ & 30 & 120 \\
MRP 1 $(\mathrm{i}=1)$ & LSP 1 $(\mathrm{j}=2)$ & 20 & 220 \\
MRP 2 (i =2) & LSP 1 $(\mathrm{j}=2)$ & 30 & 180 \\
MRP 3 (i = 3) & LSP 1 $(\mathrm{j}=2)$ & 36 & 150 \\
TS ( $=1)$ & LSP 1 $(\mathrm{j}=2)$ & 24 & 100 \\
\hline
\end{tabular}

* MRP is makeshift refuge point; TS is transfer station; LSP is long-term settlement place; TF is Traffic Flow.

Table 3. Results of Evacuation Scheme without Capital Limit

\begin{tabular}{lllll}
\hline \multicolumn{2}{l}{$\mathrm{X}$ (person/hour) } & $k^{*}=1$ & $\mathrm{k}=2$ & $\mathrm{k}=3$ \\
\hline $\mathrm{i}=1$ & $\mathrm{j}=1$ & {$[3570,3740]$} & {$[3570,3740]$} & {$[3570,3740]$} \\
& $\mathrm{j}=2$ & {$[3390,3570]$} & {$[3340,3550]$} & {$[3400,3570]$} \\
$\mathrm{i}=2$ & $\mathrm{j}=1$ & {$[2890,3060]$} & {$[2890,3060]$} & {$[2890,3060]$} \\
& $\mathrm{j}=2$ & {$[18,167]$} & {$[377,433]$} & {$[364,378]$} \\
$\mathrm{i}=3$ & $\mathrm{~J}=1$ & {$[2380,2550]$} & {$[2380,2550]$} & {$[2380,2550]$} \\
& $\mathrm{j}=2$ & {$[1342,1363]$} & {$[927,1153]$} & {$[982,1166]$} \\
\hline
\end{tabular}

* Symbol i denotes emergency assembly point; $\mathrm{j}$ denotes settlement; $\mathrm{k}$ denotes time period.

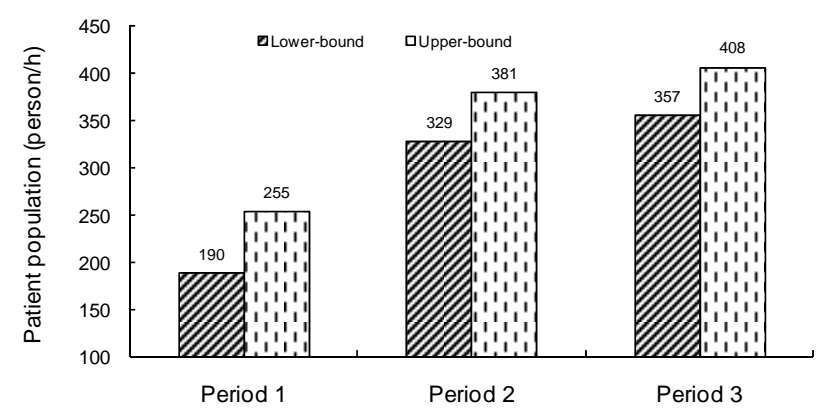

Figure 2. Results of patient population from transfer station to hospital (scenario 1).

will be polluted by the radioactive material because of the atmospheric dispersion phenomena. During disaster response, evacuation should be conducted accurately, and in a hurry; however, evacuation planning is a very complex problem involving many behavioral and management facets (Saadatseresht et al., 2009).

In this study, the planning time is designed as three hours and further divided into three time periods (each period has a time interval of one hour). The planning period is inferior to the time that the radioactive material arrivals to the shelter facilities. The emergency evacuation system includes three MRPs, two LSPs and one transfer station, where three MRPs can deliver the victim flow to LSP2 by the transfer station. The LSP1 has an existing capacity of 14500 to 15000 person, and the transfer station has a receive capacity of 280 to 300 vehicle/hour. LSP1 has an affiliated hospital offering the professional therapy for the patients infected by radioactive material; therefore, it would be received approximately [4, $8] \%$ of victim flow of LSP2. Table 1 shows the velocity of victim flow gathering into the MRPs. It is indicated that the gather velocities vary between different MRPs and different time periods. Table 2 shows the distance and maximum traffic flow of each thoroughfare. The problem under consideration is how to effectively allocate the victim flow from the three MRPs to the two LSPs to achieve maximum evacuation population within a limited time. Therefore, the IBEM model will be applied to planning the traffic routing of a certain area for one case of evacuation management.

\section{Result Analysis}

\subsection{Solutions under Scenario 1}

Since tradeoffs between economic and safety arguments exist in the management of nuclear power plant, two scenarios are analyzed based on different policies of total investment (capital) considerations. Scenario 1 represents emergency evacuation management planning without total investment limit. Table 3 shows the solutions obtained under this scenario. The results indicate that point $1(i=1)$ would have the highest evacuation rate over three time periods. The population from emergency assembly point 1 to settlement 1 would be [3570, 3740] person/hour in three periods, and to settlement 2 is [3390, 3570], [3340, 3550], [3400, 3570] person/hour in the three periods, respectively. This is because the road conditions from emergency assembly point 1 to settlements 1 and 2 are better than the other roads. The maximum vehicle flux in the above two roads would be $[210,220]$ and $[200,210]$ vehicle/ hour, while vehicle flux on the other roads is less than 170 vehicle/hour. The evacuation rate of the emergency assembly point 1 is mainly subject to the vehicle flux constraint; meanwhile, the person evacuated by emergency assembly point 1 is far from enough, making it necessary to evacuate person by emergency assembly points 1 and 2 . The evacuation population rate from emergency assembly point 2 to settlement 1 would be $[2890,3060]$ person/hour in the three periods, and to settlement 2 would be [18, 167], [377, 433], [364, 378] person/hour in the three periods, respectively. The evacuation rate from emergency assembly point 3 to settlement 1 would be $[2380,2550]$ person/hour in planning periods, and to settlement 2 would be $[1342,1363]$, [927, 1153], [982, 1166] person/hour in the three periods, respectively. Figure 2 presents the patient population flow from transfer station to settlement 1 in three periods. From the figure, the patient population flow increases from $[190,255]$ person/hour in period 1 to $[329,381]$ person/hour in period 2 , and finally reach up to [357, 408] person/hour in period 3. This is due to the fact that unforeseen circumstance would be occurred owing to people's nervousness. 


\subsection{Solutions under Scenario 2}

Under scenario 2, a total capital (investment) limit was considered for the evacuation management system. Table 4 presents the solutions for the emergency evacuation pattern under this scenario. Emergency assembly point 1 is the largest source for settlement 1 ; this is because not only road condition from assembly point 1 to settlement 1 is better that that of the others, but also their distance (from point 1 to settlement 1) is the shortest. However, due to the capacity limit of settlement 1 , there would be some population flow being transferred to settlement 2. Emergency assembly point 2 is the largest source for settlement 2, although the road condition from assembly point 2 to settlement 2 is worse than that of point 1 to settlement 2; besides, the distance from assembly point 2 to settlement 2 is the shortest. Comparing the results under scenario 1 , the evacuation population to settlement 2 is less under scenario 2; this is due to the fact that distance from emergency assembly points to settlement 2 is much larger than that to settlement 1 , such that long distance would cost more money and occupy more time.

Figure 3 shows the patient population flow from transfer station to settlement 1 during the planning horizon, the patient population would increase from [185, 245] person/hour in period 1 to $[305,340]$ person/hour in period 2 , finally achieve $[351,388]$ person/hour in period 3 . The amount of patient population is less than that under scenario 1 . This is because transporting patient would need special establishment, additional capital, and excess time, resulting in an increased system cost. The decision makers would conduct a series of publicity activities to decrease the amount of patient population.

Table 4. Results of Evacuation Scheme with Capital Limit

\begin{tabular}{lllll}
\hline \multicolumn{2}{l}{$\mathrm{X}$ (person/hour) } & $\mathrm{k}=1$ & $\mathrm{k}=2$ & $\mathrm{k}=3$ \\
\hline $\mathrm{i}=1$ & $\mathrm{j}=1$ & {$[3570,3740]$} & {$[3570,3740]$} & {$[3570,3740]$} \\
& $\mathrm{j}=2$ & {$[350,3570]$} & {$[0,979]$} & {$[298,3570]$} \\
\hline $\mathrm{i}=2$ & $\mathrm{j}=1$ & {$[1890,3060]$} & {$[2890,3060]$} & {$[2890,3060]$} \\
& $\mathrm{j}=2$ & {$[1057,2550]$} & {$[371,1518]$} & {$[944,2550]$} \\
\hline $\mathrm{i}=3$ & $\mathrm{j}=1$ & {$[2380,2550]$} & {$[2380,2550]$} & {$[2380,2550]$} \\
& $\mathrm{j}=2$ & {$[473,1870]$} & {$[782,810]$} & {$[586,1832]$} \\
\hline
\end{tabular}

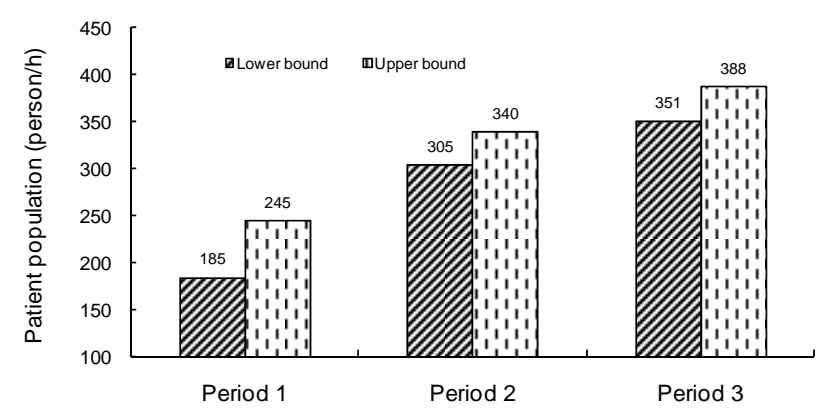

Figure 3. Results of patient population flow from transfer station to hospital (scenario 2).

\subsection{Total Evacuation Populations}

Figure 4 shows the total amounts of evacuation population (objective function values) under scenarios 1 and 2 . The solutions of objective function values are [20365, 21665] person under scenario 1 and [19125, 20205] person under scenario 2, which both represent the range of expected people needed for the evacuation. When the actual value of each variable varies within its lower and upper bounds, the expected evacuation people would change correspondingly within the solution interval. Specifically, lower decision variable values within their solution intervals (e.g., less population from emergency assembly to settlement) should be potentially used under advantageous conditions. Comparatively, higher decision variable values (i.e., more people transferred to destination) would correspond to more demanding conditions. Willingness to transfer less people to reach the destinations would guarantee a high system stability (i.e., low risk of violating system constraints); a desire to transfer more people will run into the risk of potential instability of the system (i.e., high risk of violating system constraints).

The total amount of evacuation population under scenario 1 would be higher than those under scenario 2 . This is mainly because the capital limit would lead to decreasing the evacuation population transferred to settlement 2 . Since the distance (from assembly points) to settlement 2 is larger than that to settlement 1 , the transport cost would increase with transport distance; this leads to an increased system cost. The results indicate that vehicle flux is the major impact factor under scenario 1 and capital limit is the major impact factor under scenario 2. From the above analyses, it is indicated that the solutions obtained from the proposed model are helpful in supporting decision of emergency evacuation management. The interval solutions are effective to help generate decision alternatives, where a spectrum of options could be analyzed based on the decision maker's preferences.

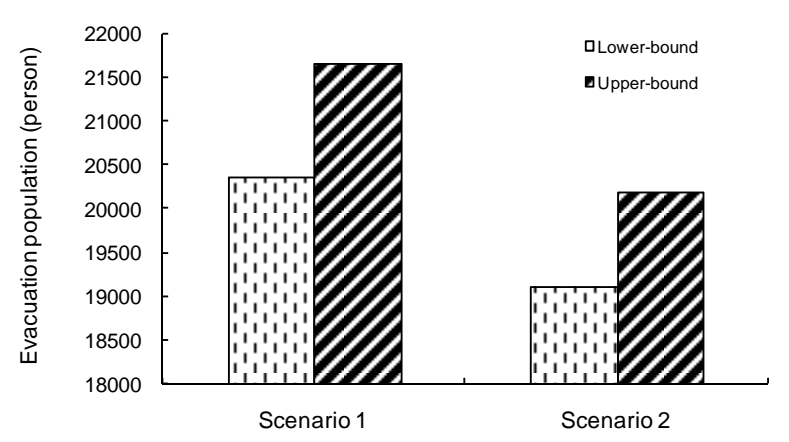

Figure 4. Results of total evacuation populations under two scenarios.

\section{Conclusions}

In this study, an interval-based evacuation management (IBEM) model has been developed in response to nuclear power plant accident under uncertainty. The IBEM model is based on interval-parameter linear programming (ILP) technique for tackling uncertainties that cannot be quantified as distribution or membership functions, since interval values are acceptable as its uncertain inputs. Through the IBEM model, evacuation population, vehicle allocation plans and 
corresponding routing strategies can be generated to evacuate large crowds after nuclear power plant accident. Considerations of emergency evacuation systems, which include the zone for evacuating to be agreed upon, the population at the risk to be identified, the time of evacuation to be predicted, the shelter of refugees to be chosen, the safe routes of evacuation to be adopted, and the levels of logistics to be offered, are integrated into a general modeling formulation, without overemphasizing one issue at the expense of neglecting the others. A variety of uncertainties can also be directly communicated into the optimization process.

Results of the case study indicate that useful solutions have been generated. A number of decision alternatives can be obtained from the developed solutions by adjusting different combinations of population shipped within the solution intervals according to projected applicable conditions. They reflect a compromise between optimality and stability of the study system, and are realistic reflections of the system complexities. Since tradeoffs between economic and safety arguments exist in the management of nuclear power plant, two scenarios are analyzed based on different policies of total capital considerations. Willingness to spend more capital for evacuation would guarantee the system stability (transfer more population); conversely, a desire to shorten the investment will run into the potential system-failure risk.

The IBEM model is applicable to evacuation problems that are associated with uncertainties expressed as discrete intervals. This is also the first attempt to strengthen the nuclearpower-plant disaster response and emergency management to mitigate their negative effects. The results suggest that the IBEM model can explicitly address complexities and uncertainties in emergency evacuation management systems and is applicable to the real-world practical nuclear accidents. The IBEM model could be further enhanced through incorporating methods of fuzzy programming and stochastic analysis into its framework to address more complex uncertainties and dynamics.

Acknowledgments. This Research was supported by the Natural Sciences Foundation of China (51190095 and 51225904), the Program for Changjiang Scholars and Innovative Research Team in University (IRT1127), and the Natural Sciences and Engineering Research Council of Canada.

\section{References}

Amin, S.M., and Gellings, C.W. (2006). The North American power delivery system: Balancing market restructuring and environmental economics with infrastructure security. Energy, 31(6-7), 967-999. http://dx.doi.org/10.1016/j.energy.2005.05.013

Birant, D. (2011). Comparison of decision tree algorithms for predicting potential air pollutant emissions with data mining models. $J$. Environ. Inform., 17(1), 46-53. http://dx.doi.org/10.3808/jei.2011 00186

Bretschneider, S., and Kimms, A. (2011). A basic mathematical model for evacuation problems in urban areas. Transport. Res. A-Pol., 45(6), 523-539. http://dx.doi.org/10.1016/j.tra.2011.03.008

Cai, Y.P., Huang, G.H., Lin, Q.G., Nie, X.H., and Tan, Q. (2009). An optimization-model-based interactive decision support system for regional energy management systems planning under uncertainty.
Expert Syst. Appl., 36(2), 3470-3482. http://dx.doi.org/10.1016/ j.eswa.2008.02.036

Chiu, Y.C., Zheng, H., Villalobos, J., and Gautam, B. (2007). Modeling no-notice mass evacuation using a dynamic traffic flow optimization model. IIE Trans., 39(1), 83-94. http://dx.doi.org/10.108 0/0740 8170600946473

Chu, G.Q., Chen, T., Sun, Z. H., and Sun, J.H. (2007). Probabilistic risk assessment for evacuees in building fires. Build. Environ., 42 (3), 1283-1290. http://dx.doi.org/10.1016/j.buildenv. 2005.12.002

Cova, T.J., and Johnson, J.P. (2003). A network flow model for lanebased evacuation routing. Transport. Res. A-Pol., 37(7), 579-604. http://dx.doi.org/10.1016/S0965-8564(03)00007-7

Davies, L.P. (2002). Risk assessment in the UK nuclear power Industry. Safety Sci., 40(1-4), 203-230. http://dx.doi.org/10.1016/S09257535(01)00037-6

Drabek, T.E. (1999). Understanding disaster warning responses. The Social Science Journal, 36(3), 515-523. http://dx.doi.org/10.1016/ S0362-3319(99)00021-X

Fan, Y.R., and Huang, G.H. (2012). A robust two-step method for solving interval linear programming problems within an environmental management context. J. Environ. Inform., 19(1), 1-9. http:// dx.doi.org/10.3808/jei.201200203

GIEREC. (2007). Greenpeace International and European Renewable Energy Council. Energy Revolution: A Sustainable World Energy Outlook: 7 .

Giugni, M. (2004). Social protest and policy change: ecology, antinuclear, and peace movements in comparative perspective. Rowman \& Littlefield: 44.

Hamza-Lup, G.L., Hua, K.A., and Peng, R. (2007). Leveraging etransportation in real-time traffic evacuation management. Electron. Commer. R. A., 6(4), 413-424. http://dx.doi.org/10.1016/ j.elerap. 2006.12.002

Hamacher, H., and Tjandra, S. (2001). Mathematical Modeling of Evacuation Problems: A State of Art. Berichte des Frauenhofer ITWM, No. 24.

Hayns, M.R. (1999). The evolution of probabilistic risk assessment in the nuclear industry. Process Saf. Environ., 77(3), 117-142. http:// dx.doi.org/10.1205/095758299529947

Huang, G.H., Baetz, B.W., and Patry, G.G. (1992). A grey linear programming approach for municipal solid waste management planning under uncertainty. Civil Engineering Systems, 9(4), 319-335. http://dx.doi.org/10.1080/02630259208970657

Huang, G.H., and Cao, M.F. (2011) Analysis of solution methods for interval linear programming. J. Environ. Inform., 17(2), 54-64. http: //dx.doi.org/10.3808/jei.201100187

Li, Y.P., Huang, G.H., and Chen, X. (2011). Planning regional energy systems in association with greenhouse gas mitigation under uncertainty. Appl. Energy, 88(3), 599-611. http://dx.doi.org/10.1016/ j.apenergy.2010.07.037

Li, Y.P., and Huang, G.H. (2012). Electric-power systems planning and greenhouse-gas emission management under uncertainty. Energ. Convers. Manage., 57, 173-182. http://dx.doi.org/10.1016/j. enconman.2011.12.018

Liu, Y., Lai, X.R., and Chang, G.L. (2006). Two-level integrated optimization system for planning of emergency evacuation. $J$. Transp. Eng.-ASCE, 132(10), 800-807. http://dx.doi.org/10.1061/ (ASCE)0733-947X(2006)132:10(800)

MacGregor-Smith, J. (1991). State-dependent queuing models in emergency evacuation networks. Transport. Res. B-meth., 25(6), 373-389. http://dx.doi.org/10.1016/0191-2615(91)90031-D

NENCR. (2010). Nuclear Energy is not a New Clear Resource. Theworldreporter.com. http://www.theworldreporter.com/2010/09/nuc lear-energy-is-not-green.html.

Pękala Ł.M., Tan R.R., Foo D.C.Y., and Jeżowski, J.M. (2010). Optimal energy planning models with carbon footprint constraints. 
Appl. Energy, 87(6), 1903-1910. http://dx.doi.org/10.1016/j.apener gy. 2009.12.012

Pidd, M., de Silva, F.N., and Eglese, R.W. (1996). A simulation model for emergency evacuation. Eur. J. Oper. Res., 90(3), 413419. http://dx.doi.org/10.1016/0377-2217(95)00112-3

Ravindra, M.K. (1990). System reliability considerations in probabilistic risk assessment of nuclear power plant. Struct. Saf., 7(2-4), 269-280. http://dx.doi.org/10.1016/0167-4730(90)90075-Z

Saadatseresht, M., Mansourian, A., and Taleai, M. (2009). Evacuation planning using multiobjective evolutionary optimization approach. Eur. J. Oper. Res., 198(1), 305-314. http://dx.doi.org/10.1016/j.ejor. 2008.07.032

Slaper, H., and Blaauboer, R. (1998). A probabilistic risk assessment for accidental releases from nuclear power plants in Europe. $J$. Hazard. Mater, 61(1-3), 209-215. http://dx.doi.org/10.1016/S0304 -3894(98)00125-3

Sorensen, J.H., Carnes, S.A., and Rogers, G.O. (1992). An approach for deriving emergency planning zones for chemical munitions emergencies. J. Hazard. Mater, 30(3), 223-242. http://dx.doi.org/ 10.1016/0304-3894(92)87001-V

Sovacool, B.K. (2008). The costs of failure: A preliminary assessment of major energy accidents, 1907-2007. Energ. Policy, 36(5), 1802-1820. http://dx.doi.org/10.1016/j.enpol.2008.01.040

Stepanov, A., and Smith, J.M. (2009). Multi-objective evacuation routing in transportation networks. Eur. J. Oper. Res., 198(2), 435-
446. http://dx.doi.org/10.1016/j.ejor.2008.08.025

Stephanie, C. (2009). In Mortal Hands: A Cautionary History of the Nuclear Age, Black Inc.: 280.

Strupczewski, A. (2003). Accident risks in nuclear-power plants. Appl. Energy, 75(1-2), 79-86. http://dx.doi.org/10.1016/S0306-2619(03) 00021-7

Tan, Q., Huang, G.H., Wu, C.Z., Cai, Y.P., and Yan, X.P. (2009). Development of an inexact fuzzy robust programming model for integrated evacuation management under uncertainty. J. Urban Plan. D-ASCE, 135(1), 39-49. http://dx.doi.org/10.1061/(ASCE) 0733-9488(2009)135:1(39)

Urbanik, T. (2000). Evacuation time estimates for nuclear power plants. J. Hazard. Mater., 75(2-3), 165-180. http://dx.doi.org/10. 1016/ S0304-3894(00)00178-3

Yamada, T. (1996). A network flow approach to a city emergency evacuation planning. Int. J. Syst. Sci., 27(10), 931-936. http://dx. doi.org/10.1080/00207729608929296

Yi, W., and Ozdamar, L. (2007). A dynamic logistics coordination model for evacuation and support in disaster response activities. Eur. J. Oper. Res., 179(3), 1177-1193. http://dx.doi.org/10.1016/ j.ejor.2005.03.077

Zhou, Q., Chan, C.W., and Tontiwachiwuthikul, P. (2011). Development of an intelligent system for monitoring and diagnosis of the carbon dioxide capture process. J. Environ. Inform., 18(2), 7583. http://dx.doi.org/10.3808/jei.201100201 